\title{
HYPOLITHIC CYANOBACTERIA COLONIZATION OF QUARTZ AT SOUTH DESERT
}

\author{
Roda F. Al-Thani \\ Department of Biological and Environmental Sciences, \\ College of Arts and Sciences, Qatar University, Qatar
}

Received 2014-01-23; Revised 2014-02-10; Accepted 2014-02-11

\begin{abstract}
Hypolithic microbial communities (found underneath rocks) were encountered in the southern desert of Qatar where quartz rocks are ubiquitous and are a substrate for hypoliths. These hypoliths thrive where extreme temperature, moisture stress and high light intensity limit the occurrence of higher plants and animal life. A small-scale ecological survey indicated that $80 \%$ of the quartz rocks in the area were colonized by green hypolithic microbial communities dominated by colonization of cyanobacteria. Using light and electron microscopic analyses; the cyanobacterial community structure of hypoliths was shown to be dominated by cyanobacteria affiliated to the genera Chroococcidiopsis, Aphanothece, Pleurocapsa, Oscillatoria, Lyngbya, Leptolyngbya, Phormidium and Scytonema).
\end{abstract}

Keywords: Qatar, Hypolithic, Quartiz, Cyanobacteria, Chroococcidiopsis

\section{INTRODUCTION}

The State of Qatar is a peninsula located between $24^{\circ} 27^{\prime}$ and $26^{\circ} 10^{\prime}$ 'north and $50^{\circ} 45^{\prime}$ ' and $51^{\circ} 40^{\prime}$ east (Fig. 1). It is $185 \mathrm{~km}$ long and $85 \mathrm{~km}$ wide, covering an area of $11,437 \mathrm{~km}^{2}$. Rocky hills and sand dunes are found in the southern parts of the country. According to its geographical location and climate, Qatar is classified as a hot subtropical desert; very hot and humid between June and August and pleasant and cool between November and February. Average annual rainfall recorded is $81 \mathrm{~mm}$. The average maximum temperature is $31^{\circ} \mathrm{C}$ and average minimum temperature is $22^{\circ} \mathrm{C}$. The morning humidity averages $71 \%$ and the afternoon relative humidity $43 \%$. As Qatar is subjected to an arid climate, it mainly possesses an arid soil, with coarse texture, shallow depth and low retention of soluble substances. The level of salinity is extremely high in the soil and in the ground water and that is attributed mainly to its flatness low altitude.

The Qatar peninsula lies on the broadest part of the interior platform of the Arabian shelf. This platform is extended through much of geological time, from southern Iraq, through eastern Saudi Arabia and Qatar. It is typified by a flat-lying relatively thin sequence of sediments laid down upon gradually subsiding basement (Ziegler, 2001). Qatar lies on an extension of the central Arabian Arch, a basement ridge that extends in an ENE direction through the Summon area. A continuation of this feature is thought to be responsible for the probable extension of the interior platform into parts of Iran north of Qatar. The known stratigraphic section in Qatar is consists of three geological ages: The Paleozoic, the Mesozoic and the Cenozoic (Nairn and Alsharhan, 1997).

Hypolithic microbial communities appear as a layer of growth attached to the underside of various translucent rock types, including flint, limestone, gypsum and sandstone (Azua-Bustos et al., 2011). However, the majority 2 are associated with translucent quartz rocks which allow transmission of sufficient light to support photosynthesis at a depth where other stressors such as moisture availability, UV irradiance and substrate stability are sufficiently minimized to allow the development of a microbial community (Cary et al., 2010; Chan et al., 2012; Pointing and Belnap, 2012). Microbial communities include different types of prokaryotic, bacteria and archaea and eukaryotic, fungi algae and mosses, microorganisms. Archaea have, until recently, been thought to be absent in both hot and cold desert 
hypoliths, as repeated attempts to detect archaeal rRNA genes using molecular methods have been unsuccessful (Warren-Rhodes et al., 2007; Pointing et al., 2009). Therefore, very little is known of their ecological role.

As hypolithic communities are primarily photosynthetic, comprising mainly cyanobacteria and unicellular algae, sufficient translucence of the overlying rocks allow for adequate light penetration which is essential (Hu et al., 2012). Cyanobacteria-dominated hypolithic communities have been described in cold deserts (Pointing et al., 2009; Wong et al., 2010; Cary et al., 2010) as well as hot deserts (WarrenRhodes et al., 2007; Lacap et al., 2011). Morphological studies have indicated that photoautotrophs, cyanobacteria, are dominant in most hypoliths studied to date from the Negev Desert, Antarctic Dry Valleys, Namib Desert, coastal Antarctic, Mojave Desert, Arctic tundra, Atacama Desert and Taklimakan Desert (Chan et al., 2012). Cyanobacteria are oxygenic phototrophic prokaryotes which appeared 3.5-2.5 billion years ago and were responsible for introducing oxygen into the atmosphere of primitive Earth. Cyanobacteria has many strategies to tolerate and avoid environmental factors and stress, even in one organism; these strategies include, stress avoidance by gliding mechanisms, stress defense by synthesis of UV-absorbing compounds, antioxidant enzymes and molecules and DNA repair mechanisms, such as excision repair and photoreactivation (Castenholz and Garcia-Pichel, 2012).

Morphological studies indicated hot arid deserts support an apparent monoculture of Chroococcidiopsis sp. (WarrenRhodes et al., 2007; Pointing et al., 2009) whilst in others, a more diverse range of taxa have been identified (Tracy et al., 2010; Stomeo et al., 2013). While polar regions supported a relatively more diverse cyanobacterial assemblage comprising various Oscillatoriales, Aphanocapsa, Aphanothece, Chroococcidiopsis and Gloeocapsa morphotypes (Zakhia et al., 2008).

The objectives of this investigation are to survey location in the desert of Qatar for phototrophic hypolithic microbial communities and to obtain information about the nature of these microorganisms.

\section{MATERIALS AND METHODS}

\subsection{Field Sampling}

The three field locations investigated were at the Southern of Qatar region. These are characterized as hot and arid sandy deserts. Sampling was carried out in February and November 2013. A small-scale randomized sampling was carried out by employing triplicate $1 \mathrm{~m}^{2}$ quadrates deployed at three separate locations across an area of $100 \mathrm{~m}^{2}$. Colonization was visually detected as a green band of microbial growth on the subsurface of white and translucent quartz rocks. For each quadrate, 10 colonized rocks were randomly selected. All rock samples were kept in sterile bags until further analysis.

\subsection{Microscopy}

Light microscopy and Scanning Electron Microscopy (SEM) was used to determine and identify the hypolithic microbial community, based on standards text books for cyanobacteria identification.

\section{RESULTS}

Distribution of quartz rocks which colonized with hypolithic microbial community were found at the three sites in South desert, Qatar (Fig. 1). Of all quartz rock types counted in these sites about 80\% showed hypolithic colonization, as based on visual examination. Hypolithic colonization was only observed on quartz rocks (Fig. 2). The size of quartz stones at these sites varied from small (0.5-1 inch), medium (1-2 inches) and large (2-5 inches). As the size of the quartz rock increased, an associated increase in hypolithon colonization was observed. All medium quartz rocks were colonized.

Hypolithic diversity most of the quartz stones buried in the soil showed abundant colonization of hypolithic microorganisms that formed a mat up to $5 \mathrm{~mm}$ thick in some places (Fig. 2c). In some cases, the biofilm extended outwards from the underside surface of the quartz, with the Exopolysaccharide (EPS) produced by the cyanobacteria agglomerating the soil particles under the rocks and in some cases the soil appear as green color biofilm under the rock.

Figure 3 light microscope images showing coccoid and filamentous cells. Figure $4 \mathrm{SEM}$ images from hypoolithic zone, (a) Overview showing coccoid cells. (b) Showing filamentous cells. (c) Heterotrophic bacteria cell. Observations by light (Fig. 3) and SEM (Fig. 4) of a well-formed biofilm of Extracellular Polysaccharides (EPS) produced by cyanobacteria were a significant component of these communities and covered the majority of sand particle surfaces.

The microscopy identification of hypolithic microorganisms composed of unicellular and filamentous cyanobacteria genera includes Chroococcidiopsis (as the primary component), Aphanothece, Pleurocapsa, Lyngybya, Leptolyngbya, Oscillatoria, Phormidium and Scytonema. 
Roda F. Al-Thani / OnLine Journal of Biological Sciences 14 (1): 57-63, 2014

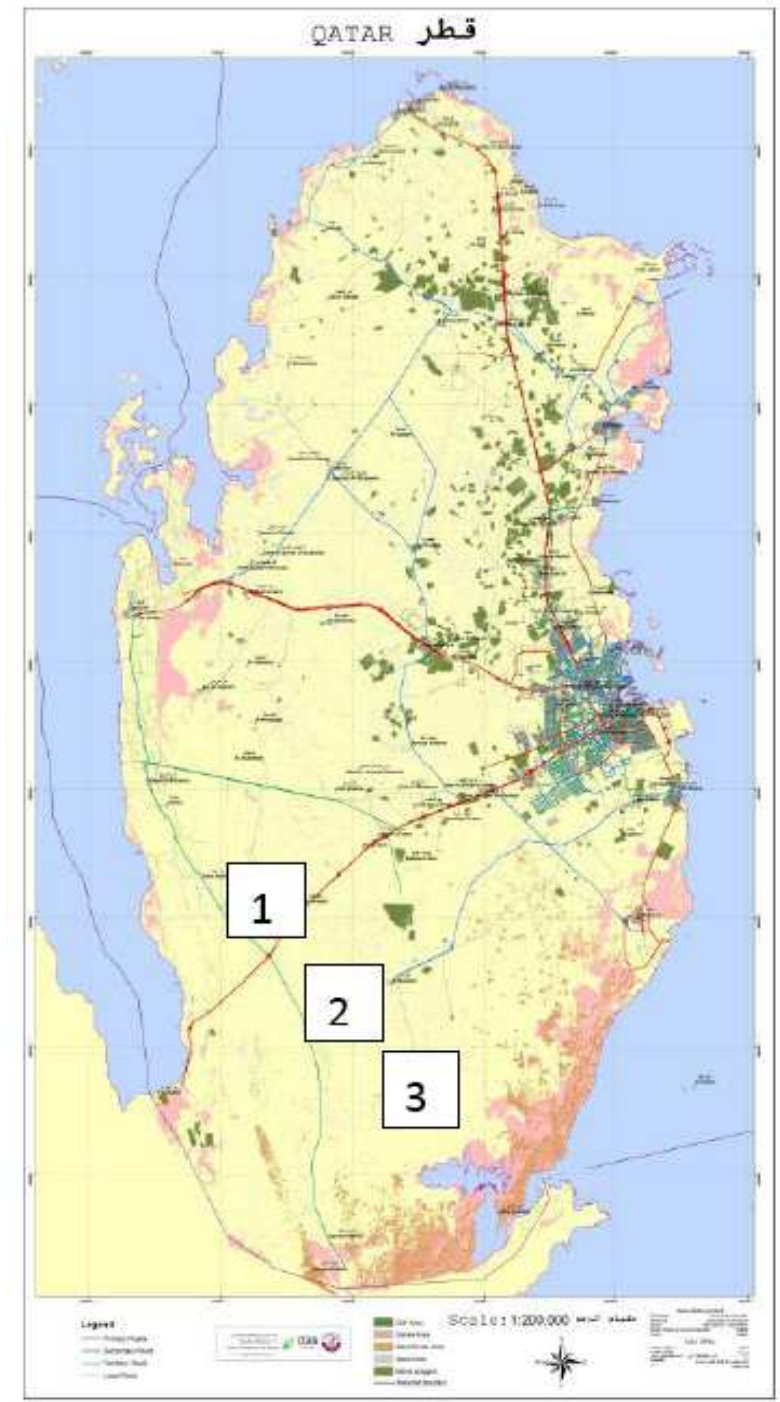

Fig. 1. Qatar map and the 3 location sites of the samples

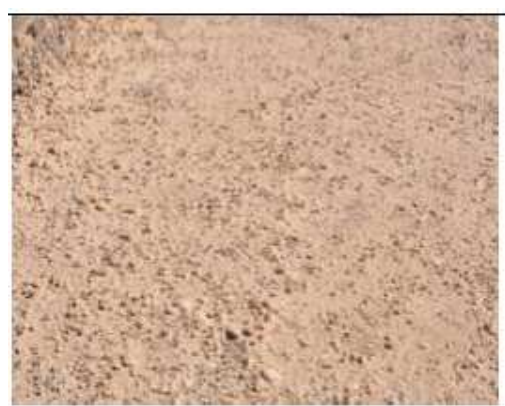

(a)

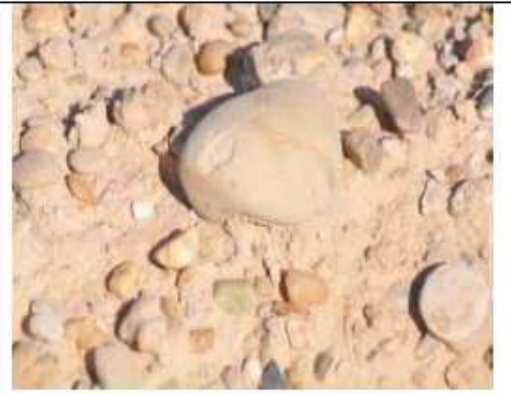

(b)

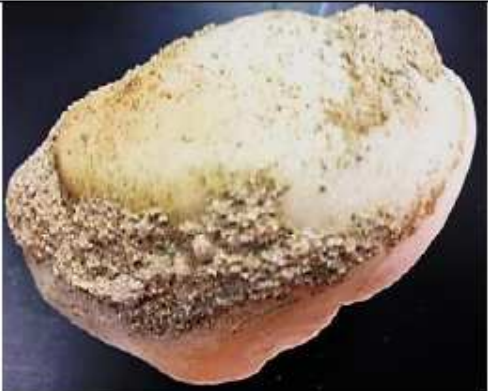

(c)

Fig. 2. Field of the quartz rocks a-b scale bar $10 \mathrm{~cm}$ and quartz rock colonized with hypolithic microbial community, scale bar $2 \mathrm{~cm}$ 


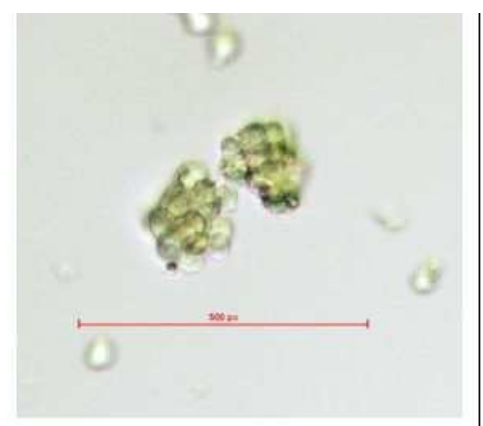

(a)

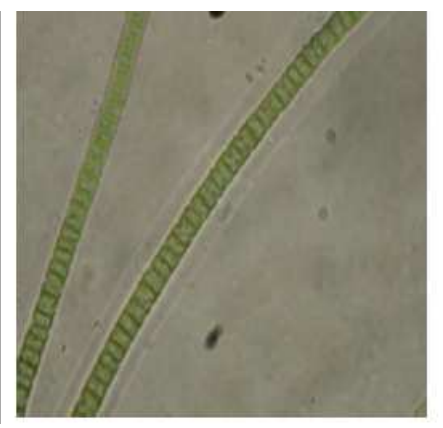

(b)

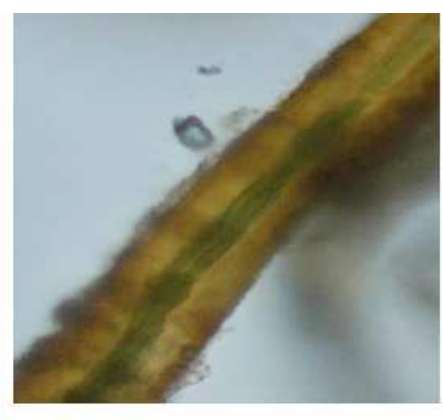

(c)

Fig. 3. Different types of cyanobacteria cells unicellular a and filaments b-c determined by light microscope

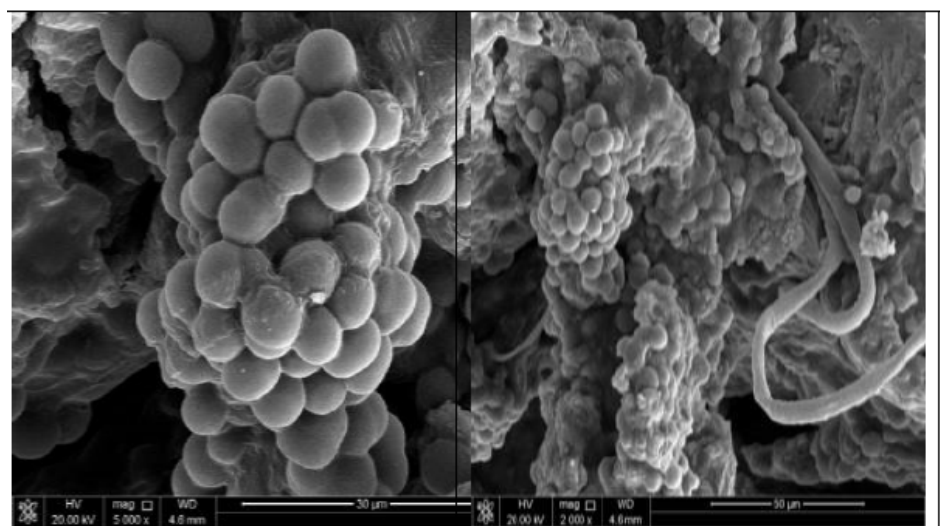

(a) (b)

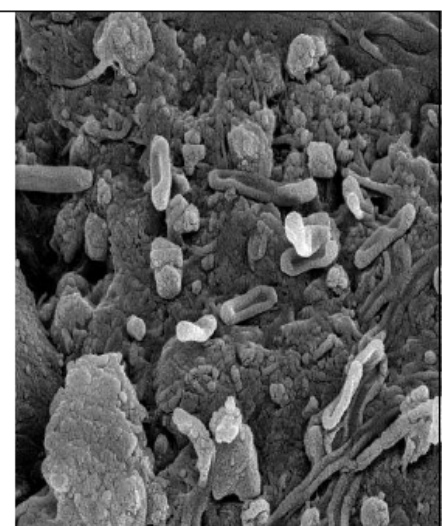

(c)

Fig. 4. (a) SEM images for Chroococidiopsis with polysaccharide sheath, (b) unicellular and filamentous cyanobacteria and (c) heterotrophic bacteria

\section{DISCUSSION}

Having surveyed many locations in Qatar, the hypolithic were only encountered in the south desert where translucent quartz rocks are widely dominate and distributed. The South desert of Qatar considered as dry because of the deficiency of rains water and high light intensity with high temperature in summer. A survey of three different sites in the sandy rocky south desert indicated that $80 \%$ of quartz rocks were colonized underneath by hypolithic. The frequency of hypolithic has been determined in a variety of hot and cold deserts to range from 0 to $100 \%$, high frequencies of 95 and $94 \%$ were documented by Cockell and Stokes (2004) on Devon and Cornwallis Island also Schlesinger et al. (2003) reported that $100 \%$ of all quartz rocks in the southern Mojave Desert are colonized by photoautotrophs. Those kinds of rocks hold the atmospheric humidity underneath and allow the growth of this microbial community with their unique characteristics to survive.
Many studies (Cary et al., 2010; Cowan et al., 2010; 2011a) suggest that soil atmospheric humidity more sufficient than soil water content as requirement water for the growth of cyanobacteria and therefore influence the diversity, distribution and development of their communities. In cold deserts, large ranges in the colonization rates were observed depending on the impact of fog (Azua-Bustos et al., 2011) and snowmelt (Pointing et al., 2009) in addition to the precipitation influence (Azua-Bustos et al., 2011). With decreasing precipitation and fog, frequency approached zero (Warren-Rhodes et al., 2006). In Qatar desert, temperature could be an important limiting factor for hypolithic growth, as temperatures in excess of $50^{\circ} \mathrm{C}$ can vaporize all the available water. Cooler early morning or late evening hours may be preferred by such hypolithic communities for their metabolic activities as host rocks could absorb water formed by condensation of dew.

Microscopy studies indicated that cyanobacteria species dominated the hypolithic communities. This is 
similar of some hyperarid Antarctic (Cowan et al., 2011b) and the Atacama Desert hypoliths (Azua-Bustos et al., 2011). The most common genera observed from south desert of Qatar were Chroococcidiopsis, Aphanothece, Pleurocapsa, Oscillatoria, Lyngbya, Leptolyngbya, Phormidium and Scytonema as found by Wong et al. (2010) the Tibetan Tundra hypoliths are colonised predominantly by Chroococcidiopsis and Phormidiumlike taxa, followed by Leptolyngbya, Nostoc and Oscillatoria species, while Arctic hypoliths are dominated by Gloeocapsa and Chroococcidiopsis. The genus Chroococcidiopsis was observed to occur exclusively in the hypolithic environment, whereas Microcoleus and Nostoc were mainly found in soilinhabiting crust samples in many location of Qatar.

Desert inhabiting Chroococcidiopsis species are capable of enter a dormancy state with desiccation onset and, resume metabolic activities when water becomes available (Grilli-Caiola and Billi, 2007). Viable cells of Chroococcidiopsis spp. were recovered from rocks from the Negev Desert after storage for 30 years (Grilli-Caiola et al., 1996). Dried aggregates of Chroococcidiopsis include live and dead cells must either protect cellular structures from damage and/or repair them upon rewetting. Billi et al. (2000) demonstrated that the desiccation surviving cells were avoiding and/or limiting genome fragmentation, preserve intact plasma membranes and phycobiliprotein autofluorescence and exhibit spatially reduced reactive oxygen species accumulation and dehydrogenase activity upon rewetting. Extracellular Polymeric Substances (EPS) may contribute to cyanobacterial desiccation tolerance by providing a repository for water and by stabilizing desiccation-related enzymes and molecules (Flemming and Wingender, 2010). Thick envelopes have been reported to encapsulate Chroococcidiopsis cells both in laboratory-dried cultures (Grilli-Caiola et al., 1996) and in natural samples, as in Chilean endoevaporites (Stivaletta et al., 2012). Indeed, the properties, structures and functions of EPS have made bacterial biofilms the most successful form of life on Earth (Flemming and Wingender, 2010). Examination of our samples after 2 years showed a stage of dormancy, very thick polysaccharides sheaths and yellow scytonemin which is known as screen for high UV. Chroococcus and Chroococcidiopsis were previously shown to produce scytonemin as a UV sunscreen and the production of this pigment was shown to be stimulated by temperature, UV-A irradiatio and periodic desiccation (Antony et al., 2012).

The ability of Chroococcidiopsis and other filamentous cyanobacteria to resist and survive in arid environments is due in part to the fact that it colonizes the underside of translucent rocks. The underside of these rocks provides enough condensed moisture for growth while the rock's translucent nature allows just enough light to reach the organism for photosynthesis to occur. In addition, they can withstand environmental stressors not currently met in nature, such as doses of ionizing radiation as high as $15 \mathrm{KGy}$ (Billi, 2012). These features make them proper photosynthetic model organisms to appreciate life's tricks to withstand extreme desiccation on Earth and investigate the survival potential of terrestrial organisms in space or in other planets, such as Mars (Azua-Bustos et al., 2012; Billi, 2012).

\section{CONCLUSION}

The study using microscopy methods demonstrated a heterogeneous distribution of the cells and the specific pigments as markers of phototrophic organisms in the hypolithic microbial community. Multiple survival strategies of the hypolithic population have been suggested. Besides being buried within the rock, the cells protect themselves from intense light and UV by producing UV-shielding pigments that become deposited in the exopolymers and may be the cause of the green autofluorescent spheres and envelopes surrounding the cyanobacterial microcolonies. The massive extracellular polymeric substances may also protect the cells from dehydration, adsorb water and nutrients and recycle the latter within the living hypolithic microbial community. Members of the genus Chroococcidiopsis are not the only photosynthetic prokaryotes in extremely dry deserts such as the Qatar desert. In Qatar desert, the hypolithic biomass is very important especially when the moisture is sufficient to conditioning and stabilization of desert soils for agricultural use and to reduce threats from dust storms. This study suggests that future investigations of hypoliths at Qatar desert need more investigation by culturing and molecular techniques to understand there taxonomy, physiology and ecology.

\section{ACKNOWLEDGEMENT}

Thanks due to Qatar University for the technical support with microscopy methods and for the centre for Geographic Information Systems (GIS) at The Ministry of Municipality and Urban Planning for providing Qatar map.

\section{REFERENCES}

Antony, C.P., C.S. Cockell and Y.S. Shouche, 2012. Life in (and on) the rocks. J. Biosci., 37: 3-11. DOI: 10.1007/s12038-012-9184-8 
Azua-Bustos, A., C. Urrejola and R. Vicuna, 2012. Life at the dry edge: Microorganisms of the Atacama Desert. FEBS Lett., 586: 2939-2945. DOI: 10.1016/j.febslet.2012.07.025

Azua-Bustos, A., C. Gonzalez-Silva, R.A. Mancilla, L. Salas and B. Gomez-Silva et al., 2011. Hypolithic Cyanobacteria supported mainly by fog in the coastal range of the Atacama Desert. Microbial. Ecol., 61: 568-581. DOI: 10.1007/s00248-010-97845

Billi, D., 2012. Plasmid stability in dried cells of the desert cyanobacterium Chroococcidiopsis and its potential for GFP imaging of survivors on earth and in space. Orig Life Evol. Biosph., 42: 235-245. DOI: 10.1007/s11084-012-9277-2

Billi, D., I. E. Friedmann, K.G. Hofer, M. Grilli-Caiola and R. Ocampo-Friedmann, 2000. Ionizingradiation resistance in the desiccation tolerant cyanobacterium Chroococcidiopsis. Applied Environ. Microbiol., 66: 1489-1492. DOI: 10.1128/AEM.66.4.1489-1492.2000

Cary, S.C., I.R. McDonald, J.E. Barrett and D.A. Cowan, 2010. On the rocks: The microbiology of Antarctic Dry Valley soils. Nature Rev. Microbiol., 8: 129138. DOI: $10.1038 /$ nrmicro 2281

Castenholz, R.W. and F. Garcia-Pichel, 2012. Cyanobacterial Responses to UV Radiation. In: Ecology of Cyanobacteria II, Whitton, B.A. (Ed.), Springer, Dordrecht, New York, ISBN-10: 9400738552, pp: 481-499.

Chan, Y., D.C. Lacap, M.C.Y. Lau, K.Y. Ha and K.A. Warren-Rhodes et al., 2012. Hypolithic microbial communities: Between a rock and a hard place. Environ. Microbiol., 14: 2272-2282. DOI: $10.1111 / \mathrm{j} .1462-2920.2012 .02821 . \mathrm{x}$

Cockell, C.S. and M.D. Stokes, 2004. Widespread colonisation by polar hypoliths. Nature, 431: 414415. DOI: $10.1038 / 431414 \mathrm{a}$

Cowan, D.A., N. Khan, S. Pointing and S. Cary, 2010. Diverse hypolithic refuge communities in the McMurdo Dry Valleys. Antarc. Sci., 22: 714-720. DOI: $10.1017 / \mathrm{S} 0954102010000507$

Cowan, D.A, J.A. Sohm, T.P. Makhalanyane, D.G. Capone and T.G.A. Green et al., 2011a. Hypolithic communities: Important nitrogen sources in Antarctic desert soils. Environ. Microbiol. Rep., 3: 581-586. DOI: 10.1111/j.1758-2229.2011.00266.x

Cowan, D.A., S.B. Pointing, M.I. Stevens, S. Craig Cary and F. Stomeo et al., 2011b. Distribution and abiotic influences on hypolithic microbial communities in an Antarctic Dry Valley. Polar Biol., 34: 307-311. DOI: $10.1007 / \mathrm{s} 00300-010-0872-2$
Flemming, H. and J. Wingender, 2010. The biofilm matrix. Nature Rev. Microbiol., 8: 623-633. DOI: 10.11038/nmicro2415

Grilli-Caiola, M. and D. Billi, 2007. Chroococcidiopsis from Desert to Mars. In: Algae and Cyanobacteria in Extreme Environments, Seckbach, J. (Ed.), Springer, Berlin, ISBN-10: 1402061110, pp: 553-568.

Grilli-Caiola, M., D. Billi and E.I. Friedmann, 1996. Effect of desiccation on envelope of the cyanobacterium Chroococcidiopsis (Chroococcales). Eur. J. Phycol., 31: 97-105. DOI: 10.1080/09670269600651251

Hu, C., K. Gao and B.A. Witthon, 2012. Semi-Arid Regions and Deserts. In: Ecology of Cyanobacteria II, Whitton, B.A. (Ed.), Springer, Dordrecht, New York, ISBN-10: 9400738552, pp: 345-369

Lacap, D.C., K.A. Warren-Rhodes, C.P. McKay and S.B. Pointing, 2011. Cyanobacteria and chloroflexidominated hypolithic colonization of quartz at the hyper-arid core of the Atacama Desert, Chile. Extremophiles, 15: 31-38. DOI: 10.1007/s00792010-0334-3

Nairn, A.E.M. and A.S. Alsharhan, 1997. Sedimentary Basins and Petroleum Geology of the Middle East. 1st Edn., Elsevier, Amsterdam, New York, ISBN10: 008054083X, pp: 878.

Pointing, S.B. and J. Belnap, 2012. Microbial colonization and controls in dry land systems. Nature Rev. Microbiol., 10: 551-562. DOI: 10.1038/nrmicro2831

Pointing, S.B., Y. Chan, D.C. Lacap, M.C.Y. Lau and J.A. Jurgens et al., 2009. Highly specialized microbial diversity in hyper-arid polar desert. Proc. Natl. Acad. Sci. USA., 106: 19964-19969. DOI: 10.1073/pnas.0908274106

Schlesinger, W.H., J.S. Pippen, M.D. Wallenstein, K.S. Hofmockel and D.M. Klepeis et al., 2003. Community composition and photosynthesis by photoautotrophs under quartz pebbles. Southern Mojave Desert Ecol., 84: 3222-3231. DOI: 10.1890/02-0549

Stivaletta, N., R. Barbieri and D. Billi, 2012. Microbial colonization of the salt deposits in the driest place of the Atacama Desert (Chile). Orig. Life Evol. Biosph., 42: 187-200. DOI: 10.1007/s11084-012-9289-y

Stomeo, F., A. Valverde, S.B. Pointing, C.P. McKay and K.A. Warren-Rhodes et al., 2013. Hypolithic and soil microbial community assembly along an aridity gradient in the Namib Desert. Extremophiles, 17: 329-337. DOI: 10.1007/s00792-013-0519-7 
Tracy, C.R., C. Streten-Joyce, R. Dalton, K.E. Nussear and K.S. Gibb et al., 2010. Microclimate and limits to photosynthesis in a diverse community of hypolithic cyanobacteria in northern Australia. Environ. Microbiol., 12: 592-607. DOI: 10.1111/j.1462-2920.2009.02098.x

Warren-Rhodes, K.A., K.L. Rhodes, L. Boyle, S.B. Pointing and Y. Chen et al., 2007. Cyanobacterial ecology across environmental gradients and spatial scales in China's hot and cold deserts. FEMS Microbial. Ecol., 61: 470-482. DOI: 10.1111/j.15746941.2007.00351.x.

Warren-Rhodes, K.A., K.L. Rhodes, S.B. Pointing, S.A. Ewing and D.C. Lacap et al., 2006. Hypolithic cyanobacteria, dry limit of photosynthesis and microbial ecology in the hyperarid Atacama Desert. Microbial. Ecol., 52: 389-398. DOI: 10.1007/s00248-006-9055-7
Wong, F.K., D.C. Lacap, M.C. Lau, J.C. Aitchison, D.A. Cowan and S.B. Pointing, 2010. Hypolithic microbial community of quartz pavement in the high-altitude tundra of central Tibet. Microbial. Ecol., 60: 730-739. DOI: 10.1007/s00248-010-9653-2

Zakhia, F., A. Jungblut, A. Taton, W. F. Vincent and A. Wilmotte, 2008. Cyanobacteria in Cold Ecosystems. In: Psychrophiles: From Biodiversity to Biotechnolgy, Margesin, R., F. Schinner, J.C. Marx and C. Gerday (Eds.), Springer, Berlin Heidelberg. ISBN-10: 3540743359, pp: 121-135.

Ziegler, M.A., 2001. Late Permian to Holocene Paleofacies evolution of the Arabian plate and its hydrocarbon occurrences. GeoArabia, 6: 445-504. 